\title{
Trachoma among the Yanomami Indians
}

J.S. Paula ${ }^{1}$

N.H. Medina ${ }^{2}$ and

A.A.V. Cruz ${ }^{1}$

\author{
1Departamento de Oftalmologia, Otorrinolaringologia e Cirurgia de Cabeça e Pescoço, \\ Faculdade de Medicina de Ribeirão Preto, Universidade de São Paulo, \\ Ribeirão Preto, SP, Brasil \\ ${ }^{2}$ Serviço Sanitário de O ftalmologia, Centro de Vigilância Epidemiológica, \\ Secretaria da Saúde do Estado de São Paulo, São Paulo, SP, Brasil
}

\section{Correspondence \\ A.A.V. Cruz \\ Departamento de Oftalmologia, \\ Otorrinolaringologia e Cirurgia \\ de Cabeça e Pescoço \\ Hospital das Clínicas, FM RP, USP \\ Av. Bandeirantes, 3900 \\ 14049-900 Ribeirão Preto, SP \\ Brasil \\ E-mail: aavecruz@fmrp.usp.br}

Research supported by SECOYA, a non-governmental organization devoted to Yanomami health.

Publication supported by FAPESP.

Received March 27, 2002

Accepted July 26, 2002

\section{Abstract}

The Yanomami are one of the last primitive groups of Indians living in Brazil. They have almost no contact with other cultures. The epidemiology of eye disease among Yanomami is virtually unknown. For the first time, a trachoma survey was conducted among Yanomami Indians in the State of Amazonas near the Venezuelan border of the Brazilian rain forest. Ophthalmic examination was carried out on a total of 613 individuals (338 males and 275 females) from eight Yanomami villages along the Marauiá River located in the upper Rio Negro Basin. Age was classified into three categories (children, adults, and elderly) and trachoma was classified into five grades: follicular, inflammatory intense, cicatricial, trichiasis, and corneal opacity. Trachoma was endemic in all villages visited. Overall, 30.3\% of the subjects had trachoma. Females were significantly more affected $(37.4 \%)$ than males $(23.9 \%)$. The inflammatory trachoma rate reached $24.9 \%$ in children and the cicatricial form increased with age, reaching $13.9 \%$ among adults and $35.21 \%$ among the elderly. Trichiasis or corneal opacities were not detected and treatment of the entire population was initiated with $1 \mathrm{~g}$ azithromycin. The detection of endemic trachoma among the Yanomami is relevant for the understanding of the epidemiology of this disease in the Brazilian rain forest and underscores the necessity for a program of trachoma control in this region.

\section{Introduction}

The Yanomami are hunter-farmer Indians that live within the South American tropical forest as aboriginals, with autonomous culture and economy. They are divided into four different groups according to linguistic divisions (Yanomam, Yanomami, Yanam and Sanima) (1) and occupy a vast territory in one of the most remote regions of the Ama-
Key words

- Trachoma

- Yanomami

- Epidemiology zon rain forest along the borders between Brazil and Venezuela. In Brazil, these Amerindians comprise about 9,400 individuals scattered throughout an area of 9.4 million hectares (2).

The Yanomami remained isolated for millennia. Sporadic contacts with European explorers occurred two centuries ago, but a sustained interaction with outsiders only took place during the 1960's when missionaries 
Figure 1. Location of the Yanomami villages along the Marauiá River. started working in their territory (3). During the seventies, the Brazilian military government launched the so-called National Integration Plan, which included the construction of a road along the northern borders of Brazil. This fact plus the discovery of gold in the eighties attracted 30,000-40,000 nonIndians to the Yanomami territory, with profound consequences for the local indigenous population (1).

The continuous social and cultural process of Yanomami assimilation has led to a progressive reduction in the quality and quantity of food consumption, to water contamination and poorer sanitation of the Indian communities (4). Even though there are scattered reports of grippe, pneumonia, malaria, tuberculosis, acute conjunctivitis, trauma, dermatological and urinary diseases (5), the whole spectrum of health problems among the Yanomami has not been fully assessed.

In this article we report for the first time that a leading cause of blindness in the world, trachoma, is threatening the eye conditions

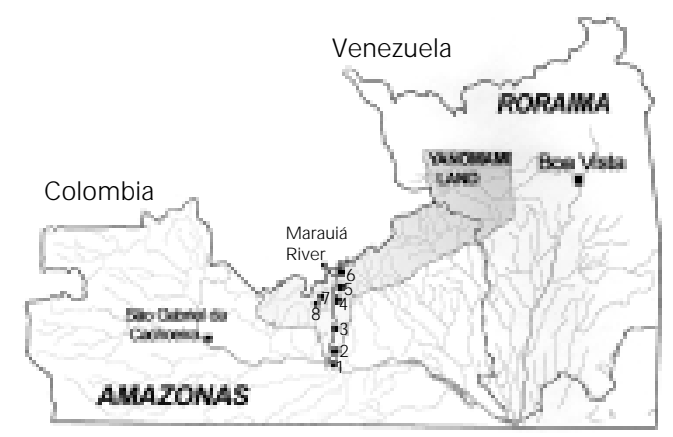

Table 1. Distribution of Yanomami Indians as a function of village, estimated and examined population.

\begin{tabular}{lccc}
\hline Village & Estimated population & Number examined & Percentage (\%) \\
\hline Ixima & 141 & 109 & 77.3 \\
Pukima & 130 & 107 & 82.3 \\
Raita & 54 & 30 & 55.6 \\
Kona & 122 & 82 & 67.2 \\
Xamata & 137 & 48 & 35.0 \\
Pohoroa & 336 & 168 & 50.0 \\
Irapajé & 63 & 49 & 77.8 \\
Bixo-Mirim & 20 & 20 & 100.0 \\
Total & 1003 & 613 & 61.1 \\
\hline
\end{tabular}

of the Brazilian Yanomami located along the Marauiá River in the north of the Amazonas State of Brazil.

\section{Material and Methods}

\section{Study area and population}

In August 2000, a cross-sectional trachoma survey was carried out among Yanomami Indians inhabiting the rain forest along the Marauiá River on the left bank of the Rio Negro in the State of Amazonas, Brazil. This research was organized by the non-governmental organization SECOYA, which provides medical assistance to the Marauiá River Yanomami. The study area is delimited by longitudes $61^{\circ}$ and $66^{\circ}$ and latitudes $00^{\circ}$ and $04^{\circ}$ (Figure 1). It is heavily forested, with temperature ranging from $22^{\circ}$ to $30^{\circ} \mathrm{C}$. These Yanomami live along the border between Venezuela and Brazil in semi-permanent villages that are separated by a half- to five-day walk from each other. Eight villages were visited. Table 1 shows their names, estimated population and number of subjects examined.

\section{Study design}

Due to the lack of any previous information about the disease in this population, the use of a sampling methodology was not feasible. During each visit the examiner tried to assess the entire population. The discrepancy between the number of people who were supposed to live in each community and the number of subjects examined is explained by the high mobility of the population, which often travels for hunting or social purposes.

All examinations were performed under natural light with $2.5 \mathrm{X}$ magnifiers according to the classification system recommended by the World Health Organization (WHO), which classifies trachoma into five grades: trachomatous inflammation-follicular or $\mathrm{TF}$ 
(presence of five or more follicles - $0.5 \mathrm{~mm}$ or greater in diameter - in the central upper tarsal conjunctiva), trachomatous inflammation-intense or TI (pronounced inflammatory thickening of the upper tarsal conjunctiva that obscures more than half of the normal deep tarsal vessels), trachomatous scarring (cicatricial) or TS (easily visible scarring in the upper tarsal conjunctiva), trachomatous trichiasis or TT (at least one eyelash rubs on the eyeball, or evidence of eyelash removal), and corneal opacity or $\mathrm{CO}$ (easily visible corneal opacity over the pupil) (6). Since age was not determined in any of the eight villages, this variable was classified into three levels: children, adults and elderly. Ocular discharge was evaluated and classified as serous, mucoid, purulent or absent. Facial cleanness was categorized as good (clean) or poor (dirty).

\section{Results}

Trachoma was found in all communities visited. Overall, 30.3\% (186/613) of the subjects had trachoma (Figure 2). Figure $3 \mathrm{~A}$ and $3 \mathrm{~B}$ show typical cases of $\mathrm{TF}$ and $\mathrm{TS}$. Females were significantly more affected $(37.4 \%)$ than males $(23.9 \%)\left(\chi^{2}=12.5, \mathrm{P}=\right.$ $0.0004)$ (Figure 4). The inflammatory trachoma $(\mathrm{TF}+\mathrm{TI})$ rate reached $24.9 \%$ among children. TS increased with age, reaching $13.9 \%$ among adults and $35.2 \%$ among the elderly (Figure 5). TT and CO were not detected in any age group.

Ocular discharge was observed in a few individuals, of whom $1.1 \%$ had serous secretion and $8.0 \%$ mucoid secretion. No purulent discharge was found. Overall, $89.8 \%$ of the subjects were classified as having clean faces.

\section{Discussion}

The epidemiology of eye diseases among the Yanomami is virtually unknown and it was thought that they were at risk of only acquiring onchocerciasis (7). Recent reports of hyperendemic trachoma in some Amazon areas close to Yanomami territory attracted our attention to this population. The data we have collected show that our suspicions were correct and the Marauiá River Yanomami indeed have a high rate of trachoma infection, about $30 \%$, comparable to other endemic regions in the Amazon State (8).

Probably because of their close contact with children, women were significantly more
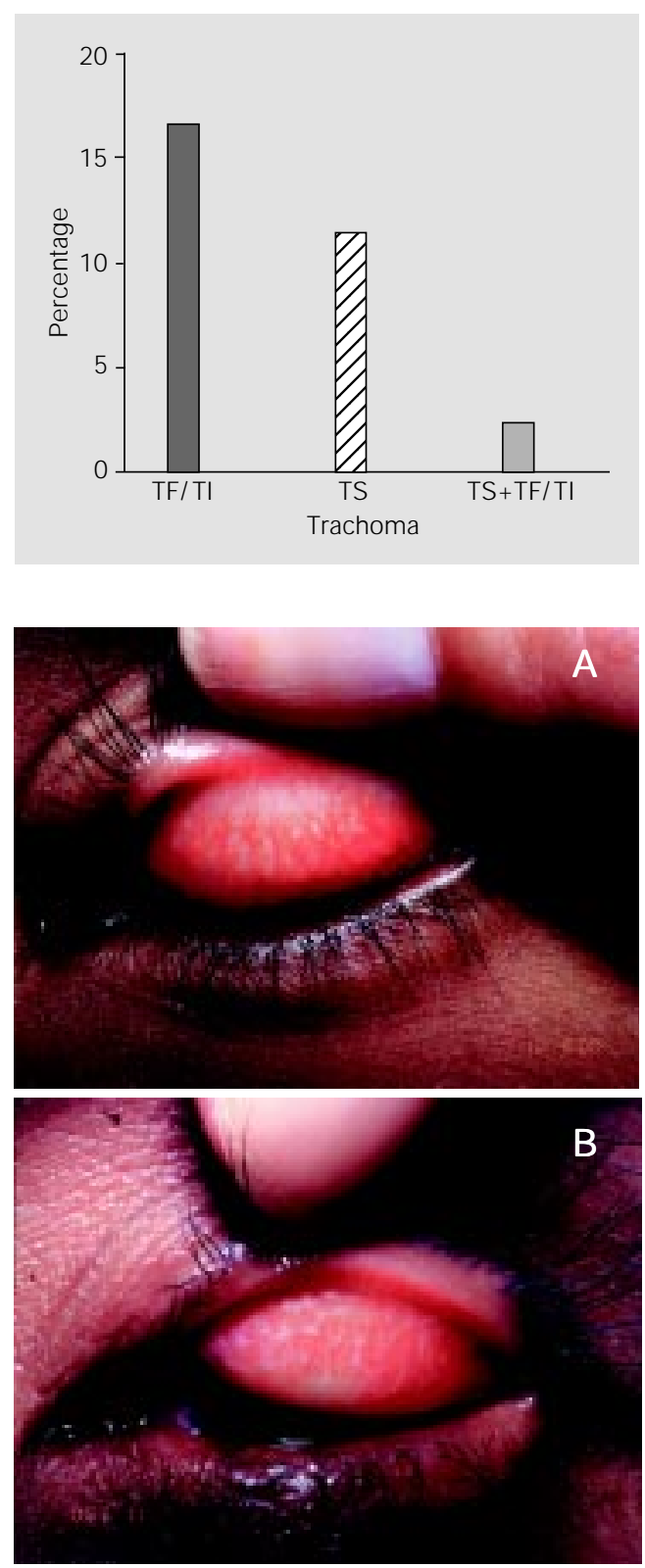

Figure 2. Trachoma among Yanomami Indians living along the Marauiá River. TF/TI = trachomatous inflammation-follicular/ trachomatous inflammationintense; TS = trachomatous scarring.

Figure 3. Trachoma in Yanomami Indians. A, Follicular trachoma in a child. B, Cicatricial trachoma in an adult. 
Figure 4. Distribution of trachoma in Yanomami Indians of the Marauiá River according to sex.

Figure 5. Distribution of forms of trachoma in Yanomami Indians of the Marauiá River according to age. $\mathrm{TF} / \mathrm{TI}=$ trachomatous inflammation-follicular/trachomatous inflammation-intense; TS = trachomatous scarring. affected than men, a classical finding that has been already reported for other endemic regions (9). The high rate of TS among the elderly (35.21\%) indicates that the disease hit the community a long time ago and the high prevalence of TF + TI among children $(24.9 \%)$ indicates a continuous state of infection. Finally, the coexistence of active and cicatricial forms in $4.5 \%$ of the adults and $1.4 \%$ of the elderly indicates that reinfection is occurring naturally in the community.

The spatial organization of the Yanomami society facilitates the spread of acute forms and thus explains the perpetuation of the infection within the community. In fact, Yanomami live in villages of 20-400 inhabitants occupying a single ring-like communal shelter with no walls or internal partitions, called "shabono". This type of living condition is an ideal situation for the circula-
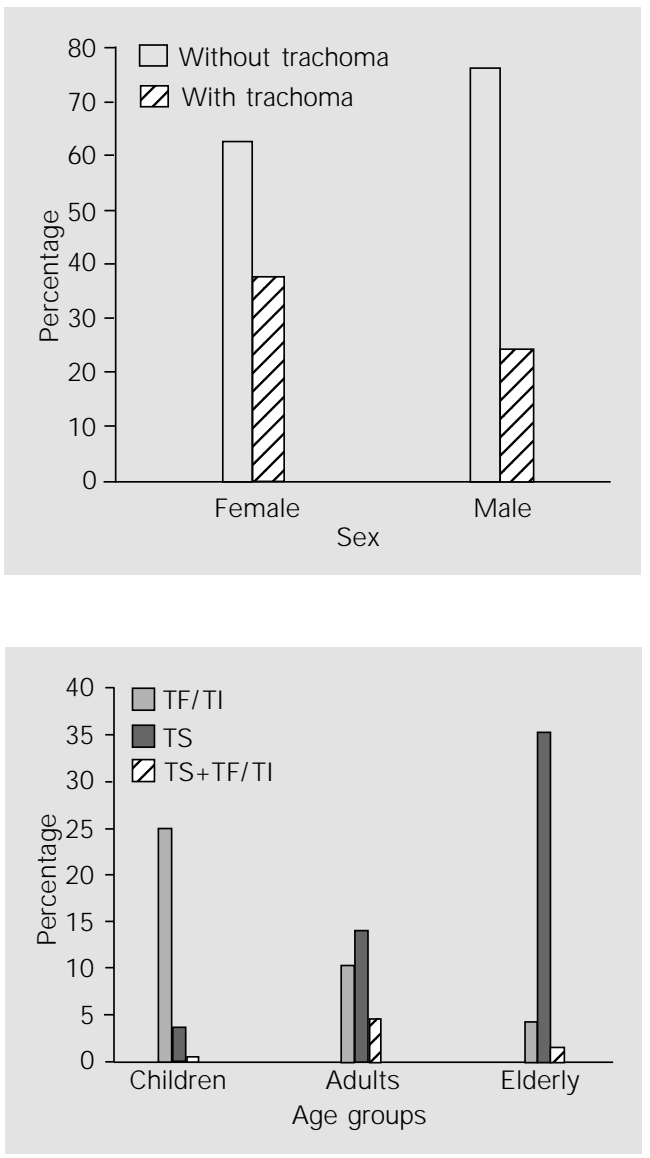

tion of Chlamydia trachomatis. However, despite the high prevalence of the disease, no cases of TT or CO were found, leading us to conclude that trachoma is not provoking blindness among the Marauiá Rivers Yanomami.

We think that the relative mildness of some characteristics of this endemic disease can be explained by Yanomami sociocultural habits. Poor facial cleanness is rare and the vast majority of the examined subjects $(89.8 \%)$ were classified as having clean faces. Their hygiene habits include frequent baths in the nearby rivers and, in addition, missionary and non-governmental organizations are upgrading their level of hygiene. In some villages they are brushing their teeth.

The detection of a high frequency of trachoma among them is relevant to the understanding of the epidemiology of this disease in the Brazilian rain forest and also underscores the necessity for an aggressive trachoma control program in this region. The Yanomami territory borders the so-called upper Rio Negro area, a huge territory occupied since ancient times by Maku, Tukano and Arawak Indians. These Indians (especially Tukanos and Arawaks) have a long history of contact with the white society which dates back to the seventeenth century when Portuguese troops moved up into the Rio Negro. As we have already reported, trachoma is endemic in the whole area of the upper Rio Negro and its prevalence reaches high levels in some Maku communities (8). Since some Yanomami from the Marauiá River often travel to the capital of the upper Rio Negro district (São Gabriel da Cachoeira city), it seems reasonable to suppose that trachoma entered the Yanomami territory through their interaction with other Indians from the upper Rio Negro. This hypothesis is supported by the fact that in São Gabriel the Yanomami eventually stay in a housing facility provided by local authorities, called the "Indian house". In this place all Indians live together in the same space. 
In order to control trachoma among the Yanomami, we tried to adapt the so-called SAFE strategy, as suggested by the WHO, to the local and cultural conditions. The SAFE strategy is based on surgery for any case of trichiasis/entropion (S), antibiotics (A), facial hygiene $(\mathrm{F})$, and environmental changes (E) (10). For the Yanomami, surgery and improvement of facial cleanness were not necessary and environmental changes were not feasible. So, we decided to treat the whole population with a single dose of $1 \mathrm{~g}$ azithromycin. This campaign was carried out by the SECOYA personnel but the results of this mass treatment have not yet been assessed.

We think that the social conditions of Yanomami Indians must be followed carefully. The relationship between poor social conditions and worsening of trachoma is well known. We believe that if the social conditions of Yanomami Indians deteriorate, blindness from trachoma will ensue. This is an endangered population.

\section{References}

1. Albert B \& Gomez GG (1997). Saúde Yanomami: Um Manual Etnolingüístico. 1st edn. Museu Paraense Emílio Goeldi, Belém, PA, Brazil.

2. Distrito Sanitário Yanomami, Roraima (1995). População Yanomami por PóloBase e Comunidades. Report of DSY/RR Fundação Nacional de Saúde, Boa Vista, RR, Brazil.

3. Smole WJ (1976). The Yanoama Indians: A Cultural Geography. Vol. 2. The Texas Pan American Series. 1st edn. University of Texas Press, Austin, TX, USA, 7-17.

4. Perez Mato S (1998). Anemia and malaria in a Yanomami Amerindian population from the southem Venezuelan Amazon.
American J ournal of Tropical Medicine and Hygiene, 59: 998-1001.

5. Francisco DA \& Oliveira CE (1996). VII Relatório de Atividades de Saúde na Área Yanomami. Report of Comissão PróYanomami, Fundação Nacional de Saúde, Roraima, Brazil (unpublished document).

6. Thylefors B, Dawson CR, J ones BR, West SK \& Taylor HR (1987). A simplified system for the assessment of trachoma and its complications. Bulletin of the World Health Organization, 65: 477-483.

7. Vivas-Martinez $S$, Basanez MG, Botto $C$, Rojas S, Garcia M, Pacheco M \& Curtis CF (2000). Amazonian onchocerciasis: parasitological profiles by host-age, sex and endemicity in southern Venezuela. Parasitology, 121 (Pt 5): 513-525.

8. Alves APX, Medina $\mathrm{NH} \&$ Cruz AAV (2002). Trachoma and ethnic diversity in the Upper Rio Negro Basin of Amazonas State, Brazil. Ophthalmic Epidemiology, 9: 29-34.

9. Tielsch J M, West J r KP, Katz J , KeyvanLarijani E, Tizazu T, Schwab L, J ohnson GJ , Chirambo MC \& Taylor HR (1988). The epidemiology of trachoma in southern Malawi. American J ournal of Tropical Medicine and Hygiene, 38: 393-399.

10. Cook J A (1999). Trachoma and the SAFE strategy. Community Eye Health, 12: 5153. 